\title{
Assessing future discharge of the river Rhine using regional climate model integrations and a hydrological model
}

\author{
M. V. Shabalova ${ }^{1}$, W. P. A. van Deursen ${ }^{2}$, T. A. Buishand ${ }^{1, *}$ \\ ${ }^{1}$ Royal Netherlands Meteorological Institute (KNMI), PO Box 201, 3730 AE De Bilt, The Netherlands \\ ${ }^{2}$ Carthago Consultancy, Oostzeedijk Beneden 23a, 3062 VK Rotterdam, The Netherlands
}

\begin{abstract}
Climate change scenarios based on integrations of the Hadley Centre regional climate model HadRM2 are used to determine the change in the flow regime of the river Rhine by the end of the 21st century. Two scenarios are formulated: Scenario 1 accounting for the temperature increase $\left(4.8^{\circ} \mathrm{C}\right.$ on average over the basin) and changes in the mean precipitation, and Scenario 2 accounting additionally for changes in the temperature variance and an increase in the relative variability of precipitation. These scenarios are used as input into the RhineFlow hydrological model, a distributed water balance model of the Rhine basin that simulates river flow, soil moisture, snow pack and groundwater storage with a $10 \mathrm{~d}$ time step. Both scenarios result in higher mean discharges of the Rhine in winter (approx. $+30 \%$ ), but lower mean discharges in summer (approx. $-30 \%$ ), particularly in August (approx. $-50 \%$ ). RhineFlow simulations also indicate that the variability of the $10 \mathrm{~d}$ discharges increases significantly, even if the variability of the climatic inputs remains unchanged. The annual maximum discharge increases in magnitude throughout the Rhine and tends to occur more frequently in winter, thus suggesting an increasing risk of winter floods. This is especially pronounced in Scenario 2. At the Netherlands-German border, the magnitude of the $20 \mathrm{yr}$ maximum discharge event increases by $14 \%$ in Scenario 1 and by $29 \%$ in Scenario 2; the present-day 20 yr event tends to reappear every $5 \mathrm{yr}$ in Scenario 1 and every $3 \mathrm{yr}$ in Scenario 2. The frequency of occurrence of low and very low flows increases, in both scenarios alike.
\end{abstract}

KEY WORDS: Climate change impact $\cdot$ Regional climate model $\cdot$ Climate change scenarios $\cdot$ Rhine discharge $\cdot$ Extreme river flows

\section{INTRODUCTION}

Understanding how climate changes impact water resources is a task of utmost importance. The increase in temperature during the 20th century is well documented on a global and regional scale (IPCC 2001). Changes in several climate parameters related to the hydrological cycle have also been detected during the last few decades. Across Europe, an increase in the mean precipitation amount (e.g. Schönwiese \& Rapp 1997, Osborn et al. 2000) and in heavy and extreme precipitation events (Gellens 2000, Osborn et al. 2000, Frei \& Schär 2001) in the cold season, a reduction in snow cover in spring (Robinson 1997, Brown 2000) and a retreat of the Alpine glaciers (Oerlemans 1994, IPCC 2001) have been revealed. Some evidence emerges that changes in climate have already resulted in an increasing frequency of floods of a number of major rivers (Groisman et al. 2001, Milly et al. 2002).

Continuous warming is the most consistent result among all the general-circulation-model (GCM) integrations of future climate, both globally and over Europe. Model integrations also suggest a continuing upward trend in winter precipitation in mid- and highlatitude Europe, a downward trend in summer precipitation in southern Europe (IPCC 2001), and a further retreat of European glaciers (Schneeberger et al. 2001). Changes in precipitation extrema, such as an 
increase in the precipitation intensity, the proportion of heavy rains, and the occurrence of very wet seasons are also projected for the future (e.g. Frei et al. 1998, Meehl et al. 2000, Jones \& Reid 2001, Räisänen \& Joelsson 2001, Palmer \& Räisänen 2002). Assessments of the impact of climate changes on river flows are in progress (e.g. Arpe \& Roeckner 1999, Bergström et al. 2001, Milly et al. 2002).

The Rhine is the longest river in Western Europe (basin $185000 \mathrm{~km}^{2}$ ) stretching from the Swiss Alps to the Dutch coast of the North Sea (Fig. 1). Its water is used for domestic consumption, irrigation, hydropower industry and prevention of salt-water intrusion from the North Sea in polder areas. The navigation on the Rhine is intense. Climate-related changes in stream flow and water availability will affect all these riverrelated activities.

It is therefore not surprising that, especially in The Netherlands, a number of projects were devoted to assessments of climate change impacts on the hydrology of the Rhine (Kwadijk 1993, Grabs 1997, Middelkoop 2000). A conceptual water balance model for the Rhine basin was specifically designed to accomplish these ends (Kwadijk 1993, van Deursen \& Kwadijk 1993). A tendency for an increase in winter runoff and

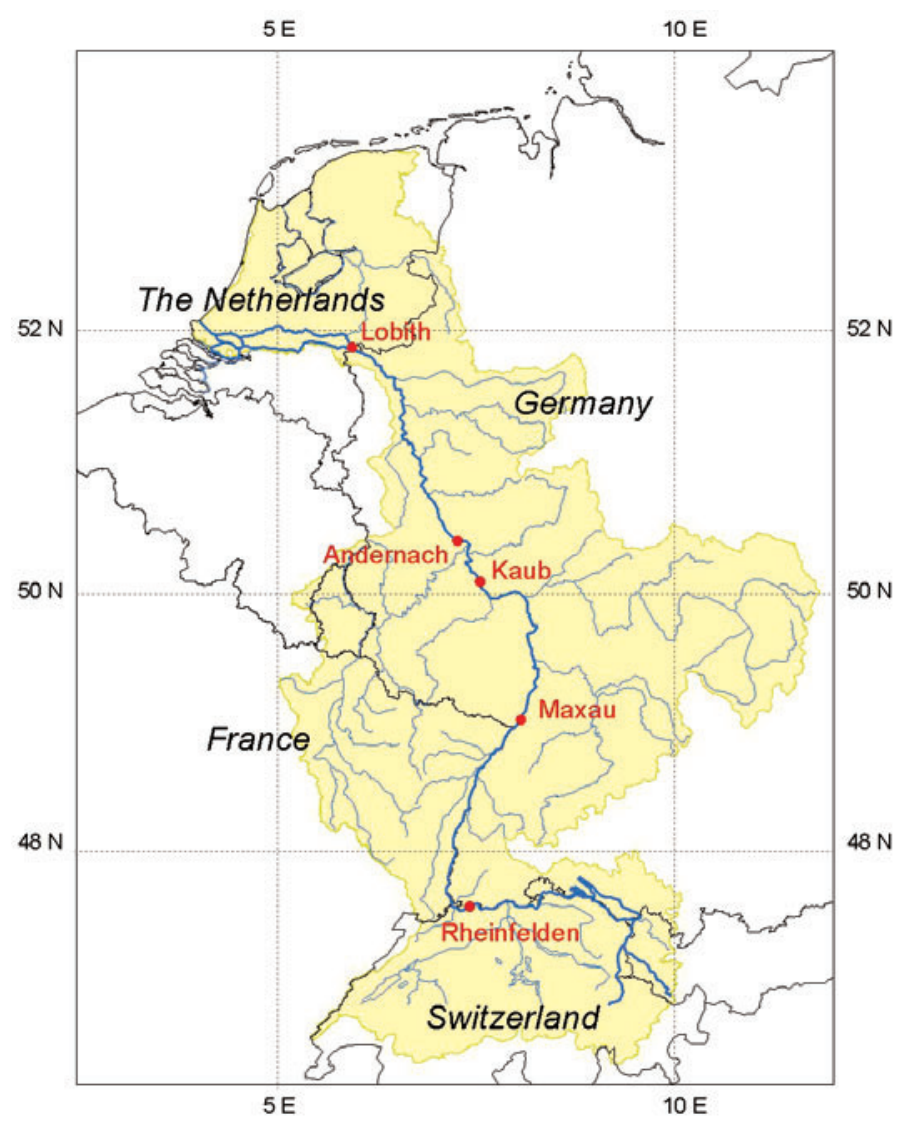

Fig. 1. Basin of the river Rhine a decrease in summer runoff of the Rhine in simulated future climates has been revealed. However, climate change scenarios used in those studies were based on rather old runs of GCMs (from the late 1980s to early 1990s) and did not account for a possible change in the variability of climatic inputs.

The present paper investigates the effect of climate change on the discharge of the Rhine using a recent simulation of future climate conducted by the Hadley Centre with the regional climate model HadRM2, and an updated version of the hydrological model of the Rhine. The latter is briefly described in Section 2. In Section 3, the analysis of the regional climate model output is performed for the Rhine basin, with emphasis on parameters that are crucial for hydrological application, such as the number of wet and very wet days, $10 \mathrm{~d}$ maximum precipitation totals, and the variances of temperature and precipitation. Climate change scenarios are formulated at the end of Section 3; one of them accounts for changes in both the mean and variability of temperature and precipitation. The results on changes in the mean and variability of the river Rhine discharge are given in Section 4. Section 5 concludes the paper.

\section{RHINEFLOW MODEL}

\subsection{Model description}

The RhineFlow hydrological model is a spatially distributed water balance model of the Rhine basin that can simulate river flow, soil moisture, snow pack and groundwater storage with a monthly (first version) or $10 \mathrm{~d}$ time step. With this relatively long time step hydraulic routing can be ignored. A full description of the RhineFlow model is given in Kwadijk (1993), van Deursen \& Kwadijk (1993), and Kwadijk \& Rotmans (1995), so only a brief summary of the model is given here, with some detail on the recent model update.

RhineFlow uses a spatial database implemented in a raster Geographical Information System. The spatial resolution is $3 \times 3 \mathrm{~km}$ in the present study. The model calculates the amount of water in the water balance compartments of the basin from meteorological data. Apart from geographical data on topography, land use, soil type and groundwater flow characteristics, the following meteorological input variables are used: the $10 \mathrm{~d}$ averages of the maximum, minimum and mean temperature, and the $10 \mathrm{~d}$ totals of potential evapotranspiration and precipitation. The minimum and maximum temperatures are used in the calculation of snow accumulation and snow melt. Potential evapotranspiration is represented as the product of a crop factor and open water evaporation, as calculated from 
meteorological data on temperature, incoming solar radiation, relative humidity and wind speed using the Penman formula. The conversion of potential to actual evapotranspiration is based on Thornthwaite \& Mather (1957).

The model consists of several routines (Fig. 2) describing water flows between the storages. The 3 main storages are: the soil moisture storage, the groundwater storage and the snow (glacial) storage. The soil moisture content is formed from precipitation plus snow melt minus actual evapotranspiration minus direct runoff, and depends on soil and land use types. If the soil moisture capacity is exceeded, then the surplus is separated into the rapid runoff and the groundwater reservoir; the latter adds a portion of water (the delayed runoff) to the total runoff. For each cell at each time step, the model output consists of the accumulated runoff from all the upstream cells, calculated according to the drainage pattern. For certain cells this output represents the discharge series at gauging stations along the river Rhine.

\subsection{Model update}

The meteorological dataset of the RhineFlow model has been updated with new daily data from the CHR (Commission International de l'Hydrologie du Bassin du Rhin) database. The spatial coverage has been substantially improved. The temperature and open water evaporation series are now available for more than 70 stations in the Rhine basin. The precipitation series are available for about 200 subcatchments in Germany, over 30 stations in France and for a $2 \times 2 \mathrm{~km}$ spatial grid in Switzerland. The 35 yr period 1961-1995 was selected as the baseline.

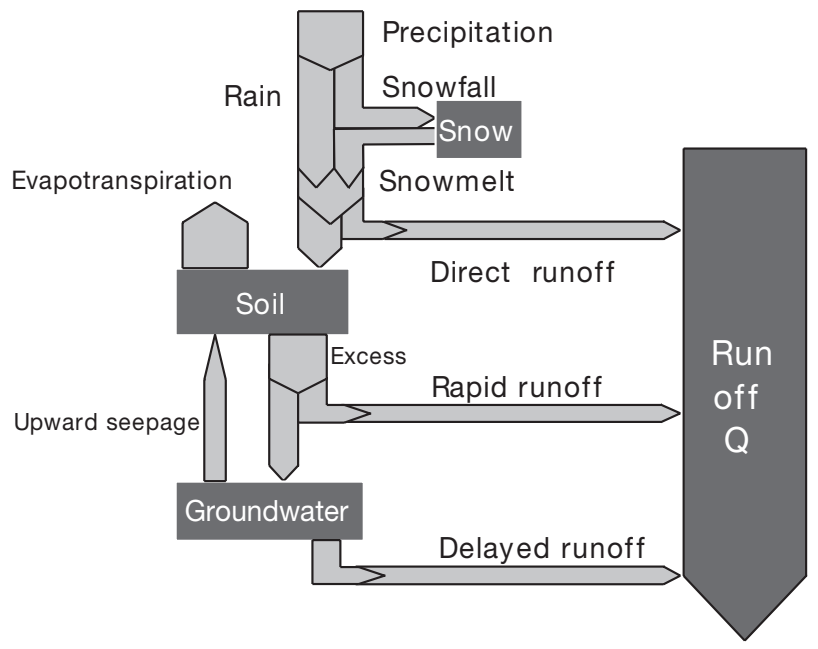

Fig. 2. Schematic of the RhineFlow model
With this meteorological update, the RhineFlow model was recalibrated using the observed discharge data at 5 gauging stations along the Rhine (Fig. 1, Table 1). The set of calibration parameters includes an adjustment parameter for the potential evapotranspiration, which is used to close the total water balance (that is, to ensure that the measured precipitation minus simulated actual evapotranspiration equals the measured discharge over the calibration period), and parameters for the separation and recession of the water flows to and from the groundwater reservoir. The parameter values were obtained by fitting the modelled discharge to observations for each of the 5 gauging stations for the period 1961-1978. The validation period was 1979-1995. The squared correlation coefficient $\mathrm{r}^{2}$ between the simulated and observed discharge is presented in Table 1 . The values of $r^{2}$ in this table are somewhat higher than the Nash \& Sutcliffe (1970) efficiency, which has often been used by hydrologists as a measure of model performance.

Fig. 3 shows the measured and simulated discharge of the Rhine (35 yr averages) at the station Lobith, located at the Netherlands-German border (Fig. 1). The comparison indicates fairly good model performance in simulating the seasonal cycle of the present-

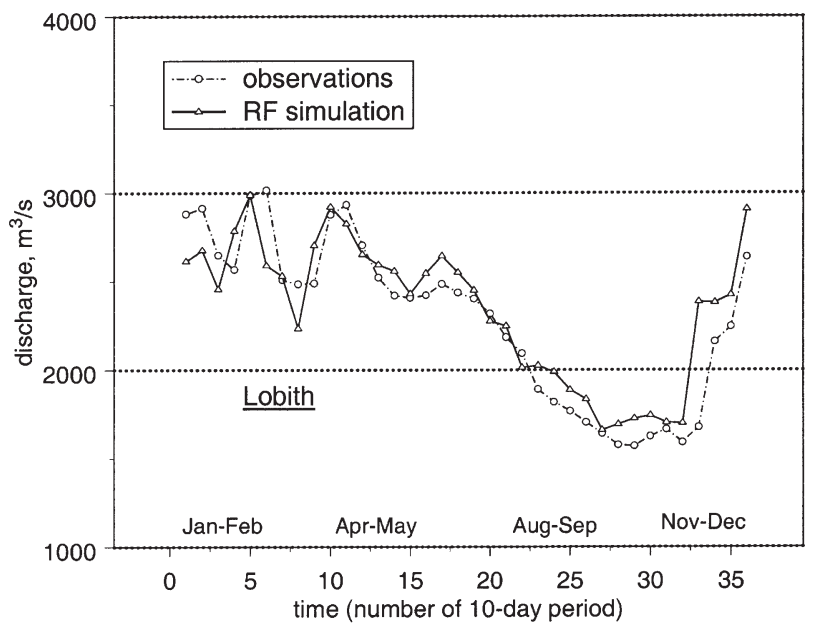

Fig. 3. Observed discharge of the Rhine at Lobith compared with that simulated by RhineFlow (RF). Shown are the average (1961-1995) discharges for the 36 periods of $10 \mathrm{~d}$ in the year 
day discharge of the Rhine. Other gauging stations along the Rhine demonstrate a similar level of agreement between the observations and simulations; for each station the annual mean is within $3 \%$ of the observed value.

The high flows are also satisfactorily reproduced by RhineFlow. The annual maximum $10 \mathrm{~d}$ discharges at Lobith for the 1961-1995 period, observed and simulated, are compared in Fig. 4a. The mean bias is small (approx. $-2 \%$ ); however, the highest discharges tend to be considerably underestimated. Although in the upper part of the basin the model tends to deviate more from the observations, the mean bias is still within $10 \%$ of the observed value at every gauging station. The low flows, on the other hand, are systematically underestimated by RhineFlow (Fig. 4b). Although in absolute terms the bias in the annual minima is small and comparable in magnitude to that in the
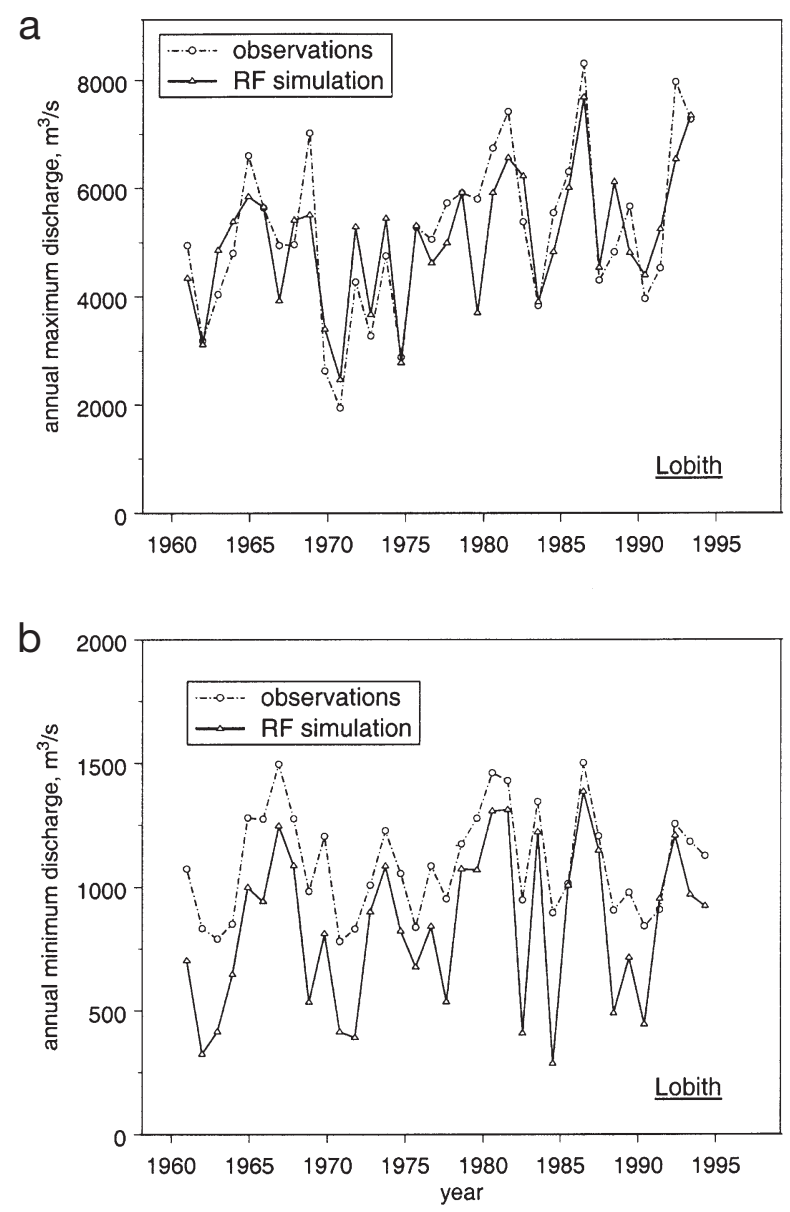

Fig. 4. Observed annual (a) maxima and (b) minima of the Rhine discharge at Lobith compared with those simulated by RhineFlow (RF). The annual maximum for a given year is computed for the period running from September of the previous year to September; the annual minimum refers to the calendar year annual maxima of the $10 \mathrm{~d}$ discharges, it is rather large in relative terms (26\% at Lobith). A better treatment of the direct runoff, soil moisture budget and groundwater discharge is needed to improve the accuracy of the simulation of low flows.

To simulate the future discharge of the Rhine, the RhineFlow model has to be run with altered meteorological inputs. Changes in temperature and precipitation for the future are obtained from climate model integrations. Changes in potential evapotranspiration are then calculated within the RhineFlow model using a relation between the change in open water evaporation and temperature for The Netherlands (Brandsma 1995). Possible effects of changes in incoming solar radiation, relative humidity and wind speed on evapotranspiration are neglected.

\section{CLIMATE CHANGE SCENARIOS}

Temperature and precipitation changes at the end of the 21st century were derived from the Hadley Centre regional climate model HadRM2 nested within the global coupled climate model HadCM2 (Johns et al. 1997). HadRM2 is a limited area model with a grid resolution of about $50 \times 50 \mathrm{~km}$, driven at its boundaries by output from HadCM2. The finer resolution of HadRM2 provides for a more realistic simulation of precipitation than that of HadCM2 (Noguer et al. 1998, Durman et al. 2001). The output from 2 integrations of HadCM2/HadRM2 was used. The control climate simulation was conducted with a constant greenhouse gas forcing representative of the second half of the 20th century. Thirty years of simulation were available for analysis. The boundary conditions for the future climate in HadRM2 were taken from a transient climate change experiment with HadCM2 performed using historical greenhouse gas forcing from 1860 to 1989 and a $1 \% \mathrm{yr}^{-1}$ increase in equivalent $\mathrm{CO}_{2}$ after this. No sulphate aerosol forcing was included. This implies rather large temperature changes, $3.0^{\circ} \mathrm{C}$ by the $2080 \mathrm{~s}$, similar to those resulting from the scenario IS92a (IPCC 1996). Twenty years (2080-2099) of perturbed climate simulation with HadRM2 were available. In the following sections, the climate change estimates were derived from the $20 \mathrm{yr}$ perturbed run and the last $20 \mathrm{yr}$ of the control run. The complete control run was used, however, in comparisons with the observed climate.

There are 89 HadRM2 grid points in the Rhine basin. The fields of precipitation and mean, maximum and minimum temperature were extracted for the Rhine area with daily resolution and averaged or accumulated over $10 \mathrm{~d}$. Actual evapotranspiration data (monthly resolution) from HadRM2 were used in checks on 
the consistency of the control climate simulated by HadRM2 with observations, as well as in checks on the calculated changes of evapotranspiration in the RhineFlow model.

\subsection{Control climate}

The differences between the HadRM2 control climate simulation and the climatology (1961-1995) of the RhineFlow model are shown in Fig. 5 for the average annual temperature and in Fig. 6 for the average total annual precipitation. The cold and wet bias of HadRM2, evident in these figures, was noted earlier by Noguer et al. (1998) for most of Europe. The Rhine basin averaged bias relative to the RhineFlow climato$\operatorname{logy}$ is $-1^{\circ} \mathrm{C}$ for temperature and $180 \mathrm{~mm}(16 \%)$ for precipitation. The wet bias is partly a result of the fact that the observed precipitation amounts were not corrected for the systematic undercatch inherent to rain gauges. The bias in mean annual actual evapotranspiration is $56 \mathrm{~mm}(12 \%)$. As a result of these biases in the HadRM2 control climate simulation, the difference between the simulated values of the area-averaged precipitation and actual evapotranspiration $(577 \mathrm{~mm}$ $\mathrm{yr}^{-1}$ ) exceeds the observed mean annual discharge at Lobith $\left(449 \mathrm{~mm} \mathrm{yr}^{-1}\right)$ by $29 \%$.

The bias of HadRM2 varies seasonally and is largest in winter for precipitation and in spring and summer for temperature. It varies also spatially, being largest in the alpine region. Locally, the bias exceeds $5^{\circ} \mathrm{C}$ in mean annual temperature and $100 \%$ in mean annual

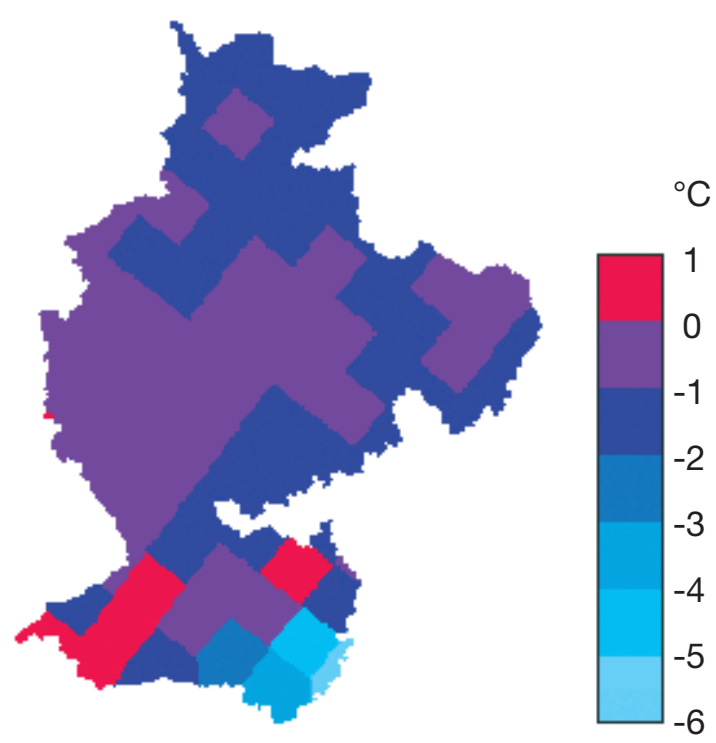

Fig. 5. Difference in mean annual temperature between the control climate integration of HadRM2 and the actual baseline climatology aggregated to the HadRM2 grid

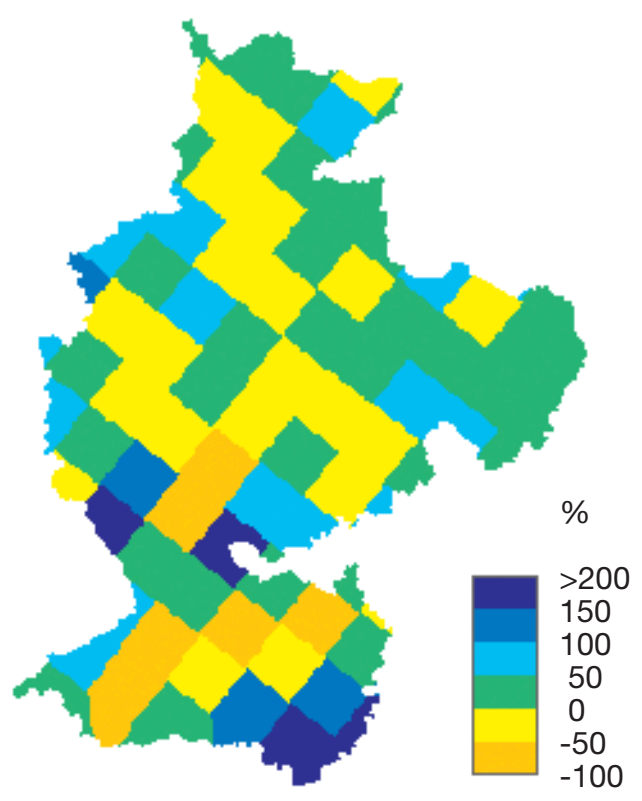

Fig. 6. Difference in total annual precipitation between the control climate integration of HadRM2 and the actual baseline climatology aggregated to the HadRM2 grid

precipitation. On the other hand, in the low part of the Rhine basin HadRM2 performs very well, even on the monthly timescale. Fig. 7 shows the observed and simulated monthly averages of precipitation and actual evapotranspiration representative of the east of The Netherlands. The values of actual evapotranspiration were derived from measurements in the Hupselse Beek experimental catchment for the period 1976-1982 (Stricker 1981, de Bruin \& Stricker 2000) and the values of precipitation from the nearby climatological station Winterswijk for the period 1951-1980. The bias in both variables is typically within $20 \%$.

In spite of bias, HadRM2 reproduces the geographical structure of the observed temperature quite well and that of precipitation reasonably. The pattern correlation with observations is 0.54 for mean annual precipitation and 0.95 for mean annual temperature. These values hardly change over the year: $0.52 / 0.46$ for precipitation and $0.91 / 0.96$ for temperature in winter/summer, respectively. The pattern correlation of the annual temperature and precipitation fields is -0.86 in HadRM2 versus -0.73 in observations.

\subsection{Changes in temperature and precipitation}

\subsubsection{Mean fields}

The perturbed minus control run values of mean annual temperature and precipitation are shown in Figs. 8 \& 9, respectively. The precipitation changes are 


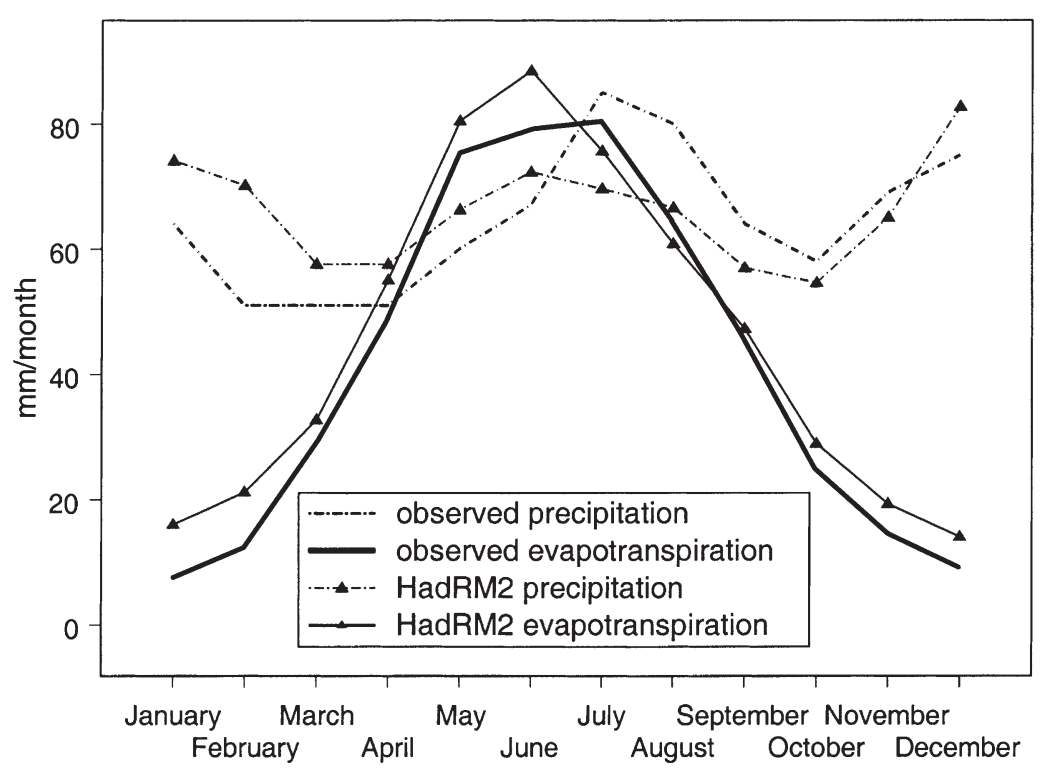

Fig. 7. Precipitation and actual evapotranspiration in the east of The Netherlands, compared with those simulated in the control climate experiment by HadRM2 for the grid point $52^{\circ} \mathrm{N}, 7.5^{\circ} \mathrm{E}$

expressed in percent of the control run means. The mean annual temperature increases over the whole area, with the largest increase in the Alps. The basin averaged warming is $5.8^{\circ} \mathrm{C}$ in winter and $4.7^{\circ} \mathrm{C}$ in summer; the annual mean warming is $4.8^{\circ} \mathrm{C}$. The corresponding change in mean annual actual evapotranspiration is $56 \mathrm{~mm}(+10 \%)$ on average; in winter the actual evapotranspiration increases by $24 \mathrm{~mm}(47 \%)$, while in summer it decreases by $6 \mathrm{~mm} \mathrm{(3 \% ).}$
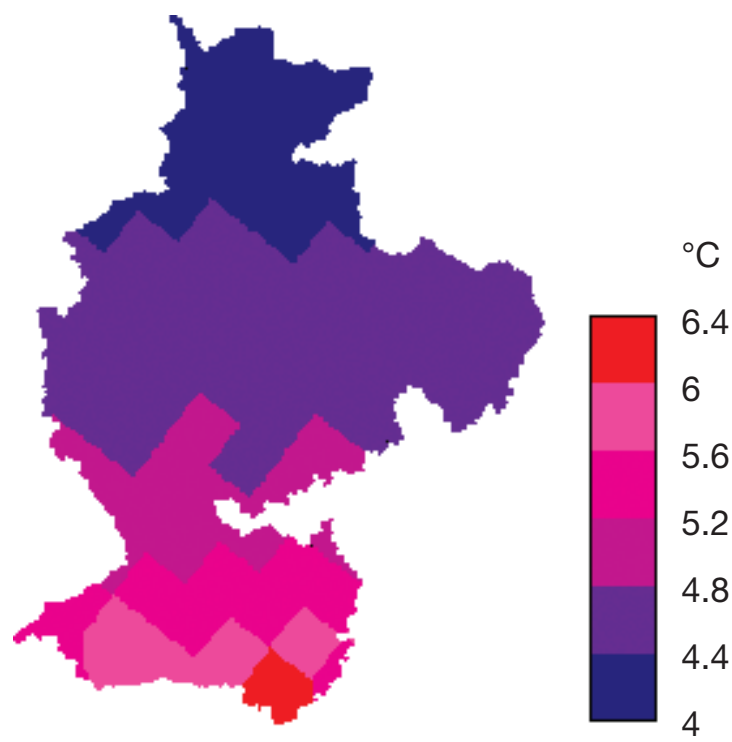

Fig. 8. Difference in mean annual temperature between the perturbed and control climate integrations of HadRM2

\section{4

4

。

Fig
The annual precipitation totals increase over the part of the basin north of $48^{\circ} \mathrm{N}$, with a maximum of about $10 \%$ in the NE corner. In the Alps mean annual precipitation decreases; at 3 grid points the decrease exceeds $10 \%$. The basin averaged annual precipitation increases only slightly (+4\%). However, the precipitation anomaly varies considerably with season: in summer precipitation decreases everywhere ( $-12 \%$ on average, up to $-29 \%$ in the Alps), while in autumn precipitation increases over the whole domain $(+15 \%$ on average, up to $45 \%$ in the Alps). In winter and spring precipitation increases on average by 6 and $9 \%$, respectively, although at a few grid points in the Alps precipitation decreases.

\subsubsection{Number of wet days and wet day precipitation amount}

The total number of wet days, $N_{\mathrm{w}}$, decreases all over the basin; the area-averaged decrease is about $30 \mathrm{~d} \mathrm{yr}^{-1}$. Seasonally, the decrease is smallest in winter (less than $5 \mathrm{~d}$ ) and largest in summer (more than $12 \mathrm{~d}$ ), especially in the Alps. A greenhouse-gas-induced reduction in the number of wet days in central Europe was also found by Räisänen \& Joelsson (2001) in 2 other regional climate model experiments. In the alpine region, the decrease in $N_{\mathrm{w}}$ is accompanied with a decrease in total precipitation (Fig. 9). In the north the total precipitation amount increases despite the decrease in $N_{\mathrm{w}}$. This is because 
the number of days with heavy precipitation (>5 mm $\mathrm{d}^{-1}$ ) increases, and so does the amount of rain they bring. Fig. 10a illustrates the change in the number of days with precipitation above different thresholds, and Fig. 10b the change in precipitation amount summed over these days. In the low and middle parts of the basin the total rainfall increases for all thresholds. For the heaviest precipitation events the change in precipitation amount is positive everywhere, including the upper part of the Rhine basin. The change in precipitation amount per rainy day (intensity) is positive for all precipitation thresholds and is largest for the heaviest precipitation events. An increase in the frequency and intensity of heavy rainfall is a prevalent result of model simulations of the
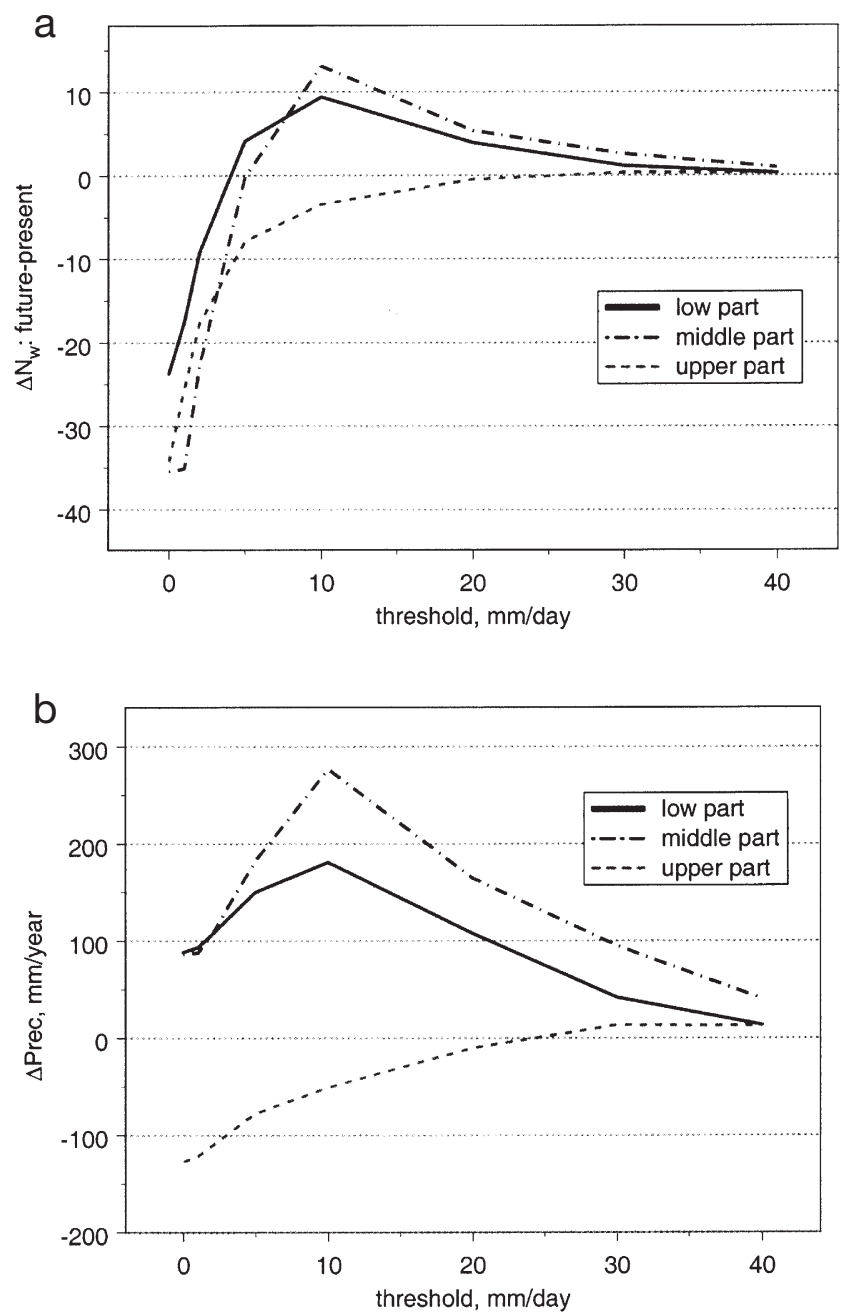

Fig. 10. (a) Change in the number of days with precipitation above a given threshold for the end of the 21st century in the HadRM2 experiment. (b) Change in precipitation amount associated with these days. The values at $x=0$ give the change in total annual precipitation. The shown locations are: $52^{\circ} \mathrm{N}, 7.5^{\circ} \mathrm{E}$ (low part of the basin), $50^{\circ} \mathrm{N}, 7.5^{\circ} \mathrm{E}$ (middle part), $47^{\circ} \mathrm{N}, 7.5^{\circ} \mathrm{E}$ (upper part) future climate (Durman et al. 2001, IPCC 2001, Jones \& Reid 2001).

\subsubsection{Variability of $10 \mathrm{~d}$ temperature and precipitation}

Together with an increase in the average temperatures, there are also systematic changes in the standard deviations of the $10 \mathrm{~d}$ mean temperatures. Table 2 shows that the standard deviation decreases in winter and increases in the other seasons. The largest increase occurs in summer. A similar pattern of variance change in mid-latitude regions has been found in other regional climate model runs for daily (Mearns et al. 1995) and monthly (Gallardo et al. 2001) temperatures. The change in the standard deviation in Table 2 is statistically significant at the $5 \%$ level for 3 of the 4 seasons, using the jackknife test for equality of variances by Beersma \& Buishand (1999).

For the $10 \mathrm{~d}$ precipitation amounts the coefficient of variation (CV: standard deviation divided by the mean) was considered as measure of variability. CV does not change if the precipitation amounts are multiplied by a constant factor, as is often done to obtain a climate change scenario. The results in Table 3 indicate a statistically significant (5\% significance level) increase in $\mathrm{CV}$ in all the seasons except for autumn. A jackknife statistic similar to that in Beersma \& Buishand (1999) was used for testing the significance of the change in CV. The increase in CV is rather uniform over the entire Rhine basin; the area-averaged annual-mean increase is $16 \%$.

Table 2. Changes in the standard deviations (SD) of the $10 \mathrm{~d}$ mean temperatures in the HadRM2 climate change experiment. The variances were averaged over the nine $10 \mathrm{~d}$ periods of the season and over all grid points in the Rhine basin. Here, the p-value refers to the observed significance level of the jackknife test; DJF: December-February, MAM: March-

May, JJA: June-August, SON: September-November

\begin{tabular}{|lcccc|}
\hline & DJF & MAM & JJA & SON \\
\hline SD $\left({ }^{\circ} \mathrm{C}\right)$, control & 4.32 & 2.95 & 2.71 & 2.58 \\
SD $\left({ }^{\circ} \mathrm{C}\right)$, perturbed & 3.57 & 3.07 & 3.66 & 2.93 \\
p-value & 0.049 & 0.302 & 0.001 & 0.020 \\
\hline
\end{tabular}

Table 3. Same as in Table 2, but for the coefficient of variation (CV) of the $10 \mathrm{~d}$ precipitation amounts

\begin{tabular}{|lcccc|}
\hline & DJF & MAM & JJA & SON \\
\hline CV, control & 0.71 & 0.65 & 0.71 & 0.93 \\
CV, perturbed & 0.89 & 0.74 & 0.91 & 0.91 \\
p-value & 0.000 & 0.002 & 0.000 & 0.938 \\
\hline
\end{tabular}


Partly because of the increased variability, the largest $10 \mathrm{~d}$ precipitation amount $P_{\max }$ increases in most of the basin, including areas where the mean annual precipitation decreases. Most notably $P_{\max }$ increases in the north, where locally it more than doubles (not shown). The number of events in the future exceeding the control-climate $10 \mathrm{~d}$ precipitation maximum is larger than 10 in the lowland part of the basin. This illustrates that the mean return period of extreme precipitation events reduces substantially in the simulated future climate.

\subsection{Scenario time series for application in RhineFlow}

The bias of the HadRM2 control climate simulation observed in Section 3.1 warns against direct use of the absolute values of the output from the HadRM2 perturbed climate run as a scenario for the hydrological model. On the other hand, the spatial structure of temperature and precipitation in the control climate run resembles that in the instrumental record. This suggests that the changes of temperature and precipitation, as simulated by HadRM2, superimposed on the baseline climatology of the RhineFlow model, may give a plausible climate change scenario. In this section, 2 scenarios are formulated: the simplest one, Scenario 1, accounting for changes in the mean fields as discussed in Section 3.2.1, and a more elaborate one, Scenario 2, that accounts additionally for changes in characteristics of variability as discussed in Section 3.2.3. The changes obtained from the HadRM2 grid are applied to the RhineFlow grid using a nearestneighbour approach.

For each point of the HadRM2 grid and for each of the 36 periods of $10 \mathrm{~d}$ in the year, the following quantities were computed: the $20 \mathrm{yr}$ averages of temperature $\bar{T}_{p e r t}$ and precipitation $\bar{P}_{\text {pert }}$ from the HadRM2 perturbed climate run, the $20 \mathrm{yr}$ averages $\bar{T}_{\text {cont }}$ and $\bar{P}_{\text {cont }}$ from the control climate run, the standard deviations of the $10 \mathrm{~d}$ temperatures $\sigma_{\text {pert }}$ and $\sigma_{\text {cont }}$ and the CV of the 10 d precipitation amounts in the perturbed and control climate run of HadRM2. To reduce the effect of sampling variability due to the rather short simulation runs, these quantities were smoothed using running means of seven $10 \mathrm{~d}$ periods.

In Scenario 1 , the difference $\bar{T}_{\text {pert }}-\bar{T}_{\text {cont }}$ is added to the 1961-1995 baseline series $T_{\text {obs }}(t)$ to form the scenario temperature series $T_{S C}(t)$ :

$$
T_{s C}(t)=T_{\text {obs }}(t)+\left(\bar{T}_{\text {pert }}-\bar{T}_{\text {cont }}\right)
$$

This changes the mean of $T_{o b s}(t)$, but has no effect on the variance. For precipitation, the ratio $\bar{P}_{\text {pert }} / \bar{P}_{\text {cont }}$ is applied to the baseline series $P_{o b s}(t)$ :

$$
P_{\text {sC }}(t)=P_{\text {obs }}(t) \times\left(\bar{P}_{\text {pert }} / \bar{P}_{\text {cont }}\right)
$$

This transformation has the effect of changing the mean of $P_{o b s}(t)$ by that ratio, but also changes the variance by the ratio squared; $C V$ remains, however, unchanged, as already noted in Section 3.2.3. The scenario series $T_{s c}(t), P_{s c}(t)$ and the baseline series $T_{o b s}(t)$, $P_{\text {obs }}(t)$ are 35 yr long (1260 periods of $10 \mathrm{~d}$ ).

In Scenario 2, the HadRM2-projected changes in the mean and variance of the $10 \mathrm{~d}$ temperatures are accounted for by using the following linear transformation of $T_{o b s}(t)$ :

$$
T_{s c}(t)=\left[T_{o b s}(t)-\bar{T}_{o b s}\right] \times \sigma_{\text {pert }} / \sigma_{\text {cont }}+\bar{T}_{\text {obs }}+\left(\bar{T}_{\text {pert }}-\bar{T}_{\text {cont }}\right)
$$

Here $\bar{T}_{o b s}$ stands for the $35 \mathrm{yr}$ averages of the observed $10 \mathrm{~d}$ temperatures (36 values). This transformation changes the mean of $T_{o b s}(t)$ as in Scenario 1, but also changes the standard deviation of $T_{o b s}(t)$ by the ratio $\sigma_{\text {pert }} / \sigma_{\text {cont }}$.

A transformation similar to Eq. (2) for precipitation to account for the increase in CV results in negative values of $P_{S C}(t)$ for a number of $10 \mathrm{~d}$ periods. Simple replacement of these negative values by zeros increases the mean additionally by about $4 \%$. One way to avoid these negative values is to fit Weibull distributions to the observed $10 \mathrm{~d}$ precipitation amounts (36 different distributions for each grid point), then to change the estimated parameters of these distributions according to the HadRM2 integrations and finally to compute the new precipitation values. This method was used in the present study; details are given in Appendix 1. In Scenario 2, the mean of $P_{o b s}(t)$ changes as in Scenario 1, but also the increase in $\mathrm{CV}$ is consistent with that in the HadRM2 experiment. Scenario 2 also implies an increase in the proportion of very small 10 d rainfall amounts; in a crude approximation, this may be regarded as a representation of the increase in the number of dry days in the simulated future climate as discussed in Section 3.2.2.

\section{CHANGES IN RIVER FLOWS}

\subsection{Seasonal cycle}

Changes in the mean discharge of the Rhine under Scenarios 1 and 2 are presented in Fig. 11 for Lobith and Rheinfelden. The relative changes from Scenario 1 are shown in Fig. 12. Scenario 2 brings almost the same pattern of change in mean discharge as Scenario 1. At Lobith, the mean annual discharge decreases by $3 \%$ in Scenario 1 and by $5 \%$ in Scenario 2 . While the mean annual discharge does not change much, there is a marked redistribution of discharge within the year. Table 4 shows the changes in the annual and seasonal means for a number of water balance components of the Rhine basin. Shown are averages over the areas upstream of Lobith, Maxau and Rheinfelden. 

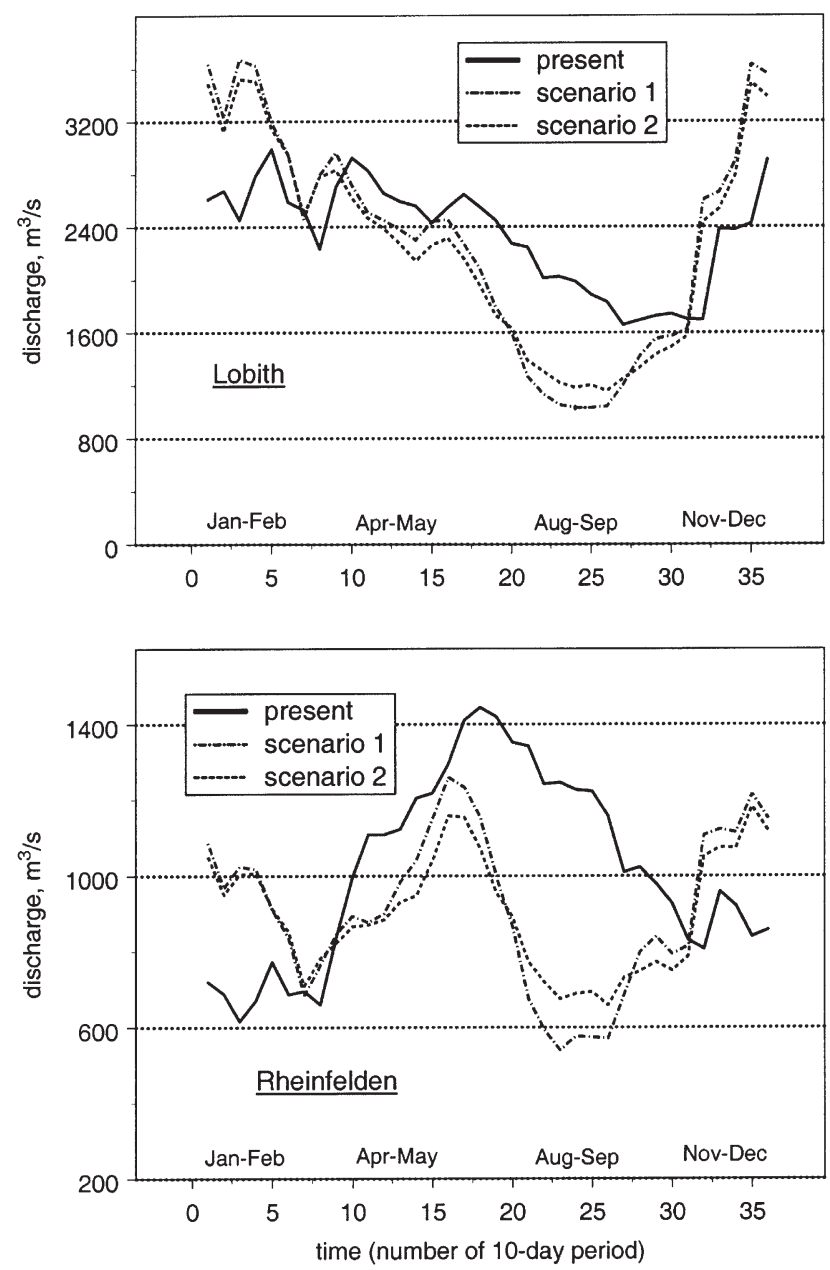

Fig. 11. Discharge of the Rhine at Lobith and Rheinfelden, as simulated by RhineFlow for the present-day climate and in 2 scenario runs. Shown are the average discharges for the 36 periods of $10 \mathrm{~d}$ in the year

During winter the discharge increases throughout the Rhine, with the largest relative changes in the alpine region (+37\% at Rheinfelden in Scenario 1 and $+35 \%$ in Scenario 2). This is due to the increase in precipitation and the fact that warming leads to a decrease in the amount of precipitation that is stored as snow and to an increase in early melt. During summer the discharge of the Rhine decreases, by $31 \%$ ( $29 \%$ in

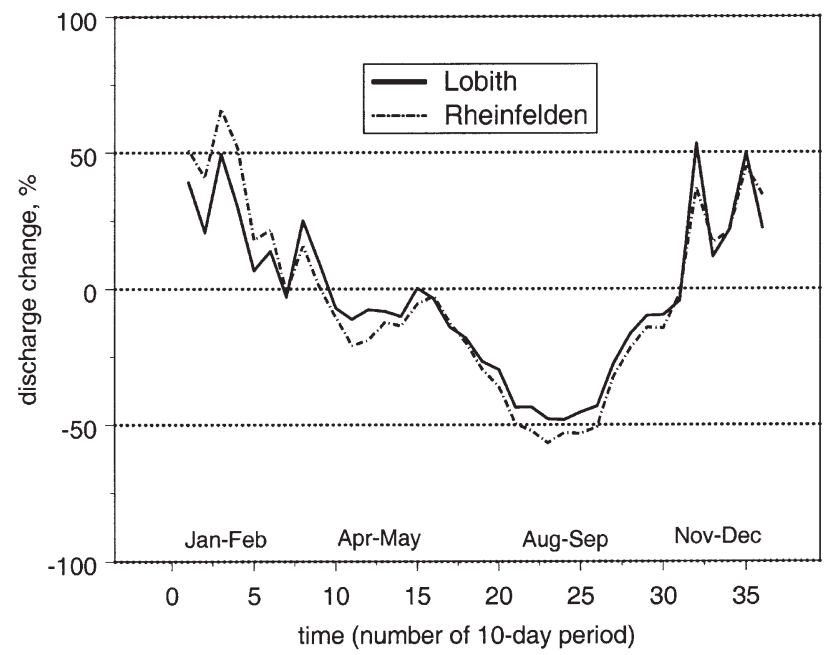

Fig. 12. Change in the Rhine discharge (\% of the present-day discharge) at Lobith and Rheinfelden, as simulated by RhineFlow in climate change Scenario 1

Scenario 2) at Lobith and by $35 \%$ (33\% in Scenario 2) at Rheinfelden. In August, the reduction of discharge is as large as $50 \%$ at Rheinfelden. This is in line with the decreased summer precipitation and, in the Alps, with the increased actual evapotranspiration. In the northern part of the basin the evapotranspiration hardly changes, because of sharply decreasing soil moisture. Also, due to the general decrease in snow storage in the Alps, the input from snow melt in the early summer decreases. The mean autumn and spring discharges at Lobith do not change much, due to the balance between changes in precipitation, snow pack and evapotranspiration; in the alpine area, there is some decrease in the mean discharge in these seasons. Fig. 11 indicates that the present-day gradual decrease in the mean discharge from September to November will be reversed in the future.

The basic pattern of change in discharge depicted in Table 4 is in qualitative agreement with scenario discharges for the Rhine obtained earlier (e.g. Kwadijk \& Rotmans 1995). The reason is that the broad-scale pattern of discharge change is, to a large extent, controlled by the temperature change that is similar across Central Europe in most climate model integrations

Table 4. Changes (\% or $\mathrm{mm}$ ) in the main components of the water balance in the Rhine basin under Scenario 1 . Shown are annual and seasonal averages over the area upstream of the indicated station. Changes in snow cover are presented in mm of water equivalent. Abbreviations as in Table 2

\begin{tabular}{|c|c|c|c|c|c|c|c|c|c|c|c|c|}
\hline \multirow{2}{*}{ Stn } & \multicolumn{3}{|c|}{ Discharge (\%) } & \multicolumn{3}{|c|}{ Actual evapotranspiration (\%) } & \multicolumn{3}{|c|}{ Soil moisture (\%) } & \multicolumn{3}{|c|}{ Snow cover (mm) } \\
\hline & Year & DJF & JJA & Year & DJF & JJA & Year & DJF & JJA & Year & DJF & JJA \\
\hline Lobith & -3.4 & 28.9 & -30.6 & 12.9 & 24.5 & 1.2 & -6.2 & 0.2 & -12.2 & -54 & -61 & -46 \\
\hline Maxau & -6.0 & 30.2 & -33.9 & 20.2 & 29.6 & 13.2 & -2.3 & -0.2 & -4.7 & -105 & -120 & -90 \\
\hline Rheinfelden & -4.6 & 37.4 & -34.7 & 27.5 & 46.3 & 15.8 & -1.6 & $\sim 0$ & -3.4 & -150 & -171 & -130 \\
\hline
\end{tabular}


regardless of their age. Note that a similar pattern can be found in the scenario discharge for other European rivers for which snow feeding is important (e.g. Arnell 1999). For the Rhine, a scenario with the mean temperature change only (Eq. 1a) and no change in precipitation results in a moderate decrease $(-10 \%)$ in the mean discharge during April-October and in an increase in discharge in winter by about $+15 \%$. The change in precipitation modifies this pattern by increasing the discharge already in late autumn and by shortening though deepening the period of runoff reduction in summer.

In the current version of RhineFlow, the changes in potential evapotranspiration depend only on changes in temperature. This may introduce an inconsistency between changes in actual evapotranspiration calculated in RhineFlow and in HadRM2. The basin-averaged increase in the annual actual evapotranspiration in RhineFlow (64 mm, 13\%) corresponds reasonably well to that in the HadRM2 model (56 mm, 10\%). In summer, both models indicate a very small change in the area-averaged actual evapotranspiration. In winter, however, the increase in actual evapotranspiration in RhineFlow $(7 \mathrm{~mm}$ ) is about 3 times smaller than that in HadRM2 (24 mm). This points to a problem with the parametrization of potential evapotranspiration in the RhineFlow model. The full Penman-Monteith formula (McKenney \& Rosenberg 1993), accounting for changes in relative humidity, wind speed and solar radiation, in addition to temperature, would give better estimates of the changes in evapotranspiration. However, it requires an extensive additional amount of data. These data were not available in the present study.

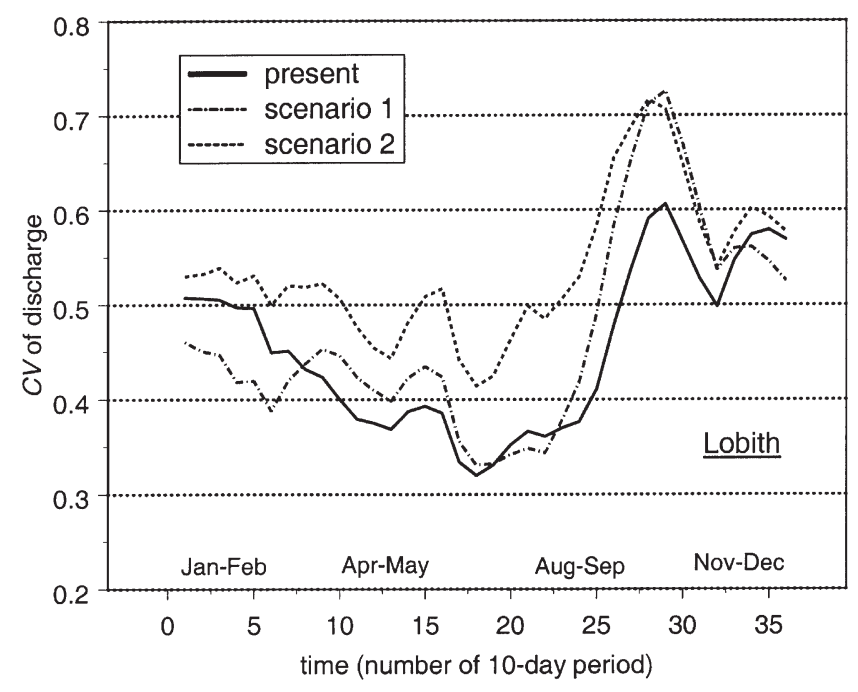

Fig. 13. Coefficient of variation (CV) of the Rhine discharge at Lobith, as simulated by RhineFlow for the present-day climate and in 2 scenario runs. Shown are the values for the 36 periods of $10 \mathrm{~d}$ in the year

\subsection{Variability of discharge}

Scenario 1 results in a significant change in relative variability of discharge throughout the Rhine even though there is no change in relative variability in the precipitation input. Fig. 13 illustrates this for Lobith. The increase in CV in autumn by about $20 \%$ is statistically significant at the $5 \%$ level in the jackknife test of Beersma \& Buishand (1999). This effect appears to be a reflection of the non-linear relationships between precipitation and runoff (Arnell 1999). Under Scenario 2, the increase in $\mathrm{CV}$ of discharge is larger than that in Scenario 1, and it is statistically significant at the $5 \%$ level in 3 seasons out of 4 .

\subsection{Extremes}

The annual maxima $Q_{\max }$ of the discharge series are described here by the Gumbel distribution that takes the form

$$
F(x)=\operatorname{Pr}\left(Q_{\max } \leq x\right)=\exp \{-\exp [-(x-\xi) / \alpha]\}
$$

where $\xi$ and $\alpha$ are the parameters of the distribution. The inverse transform of Eq. (3) gives the following for the standard or reduced variate $y$ :

$$
y=(x-\xi) / \alpha=-\ln \{-\ln [F(x)]\}
$$

The mean return period $T(x)$ of an exceedance of a value $x$ follows from $T(x)=1 /[1-F(x)]$.

Fig. 14 shows a Gumbel plot of the annual maxima of the $10 \mathrm{~d}$ discharge for the present-day run and 2 scenario runs at Lobith. In the figure, the ithsmallest value is plotted against $y_{i}=-\ln \left[-\ln \left(F_{i}\right)\right]$ with $F_{i}=(i-0.3) /(n+0.4)$, where $n=35$ is the sample size

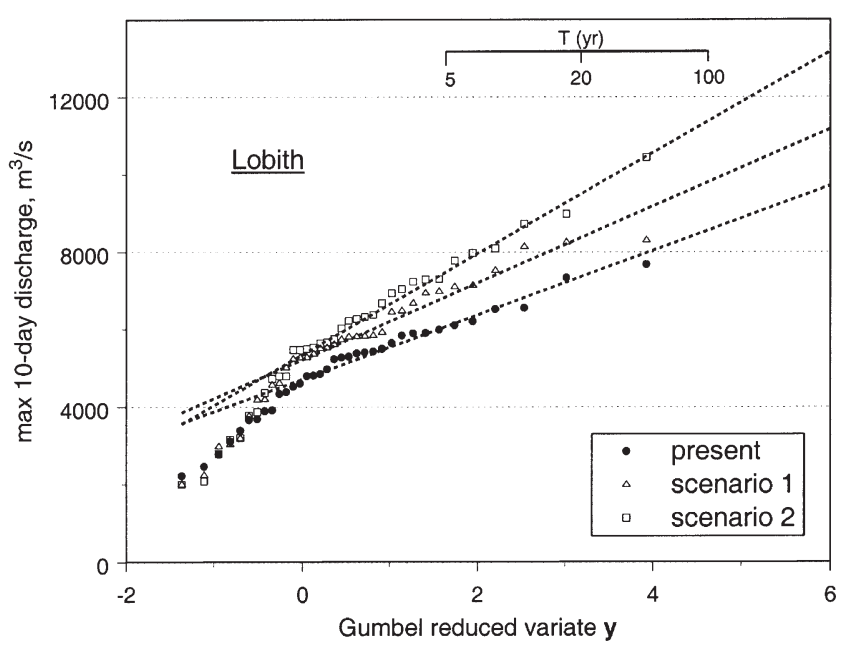

Fig. 14. Annual maxima of the $10 \mathrm{~d}$ discharge at Lobith, as simulated by RhineFlow for the present-day climate and in 2 scenario runs. The straight lines are based on the maximum likelihood estimates of the parameters $\xi$ and $\alpha$ (Eq. 3) for the largest 20 values 
(Harter 1984). If these values came from a Gumbel distribution, they would follow a straight line. Fig. 14 shows that this does not apply to the entire range of the annual maxima. The straight lines in the figure are based on the maximum likelihood estimates of the parameters $\xi$ and $\alpha$ (Eq. 3) for the sample censored at the 20th-largest value of $Q_{\max }$ (Harter \& Moore 1968). Fig. 14 implies clear changes in the magnitude and occurrence of extreme events. The magnitude of the 20 yr maximum discharge event, for example, increases by $14 \%$ in Scenario 1 and by $29 \%$ in Scenario 2 . The return period of the present-day $20 \mathrm{yr}$ event reduces to $5 \mathrm{yr}$ in Scenario 1 and to $3 \mathrm{yr}$ in Scenario 2. It is worth pointing out that the largest discharge events in the 3 runs occur in different parts of the $35 \mathrm{yr}$ period and do not coincide with the time of the absolute maximum of precipitation.

The results for Rheinfelden are somewhat different. There, the lower tail of the distribution of $Q_{\max }$ does not change, but for return periods in excess of about $3 \mathrm{yr}$ the magnitude of events increases; for the $20 \mathrm{yr}$ maximum discharge event the magnitude increases by about $20 \%$ in both scenarios (not shown).

Fig. 15 shows the changes in the distribution of the annual maximum discharge events within the year for Lobith and Rheinfelden. At both stations, and in both scenarios, the annual maxima tend to be more frequent in winter, thus suggesting an increasing risk of winter floods. There is also a clear tendency towards a decrease in the number of annual maximum events in summer at both stations.

Regarding low flows, Table 5 shows, for the presentday conditions and under Scenarios 1 and 2, the proportion of $10 \mathrm{~d}$ periods in the $35 \mathrm{yr}$ long series that the Rhine discharge at Lobith is below a certain threshold. For the $1600 \mathrm{~m}^{3} \mathrm{~s}^{-1}$ threshold, this proportion increases by $30 \%$ in both scenarios, while for the $1000 \mathrm{~m}^{3} \mathrm{~s}^{-1}$ threshold this number doubles. River discharges below $1000 \mathrm{~m}^{3} \mathrm{~s}^{-1}$ impose severe limitations on navigation in The Netherlands (Grabs 1997). This discharge is exceeded $95 \%$ of the time. Because RhineFlow underestimates the low flows (Section 2.2), the simulated present-day discharge exceeds the $1000 \mathrm{~m}^{3} \mathrm{~s}^{-1}$ threshold in $92 \%$ of the cases. In Scenarios 1 and 2, this level will be exceeded $83 \%$ of the time only. The timing of the minimum discharge shifts from SeptemberDecember to August-November in these scenarios.

\section{DISCUSSION AND CONCLUSION}

Two scenarios for temperature and precipitation in the Rhine basin at the end of the 21 st century, warmer and on average wetter than the present-day climate, were derived from the HadRM2 experiment and
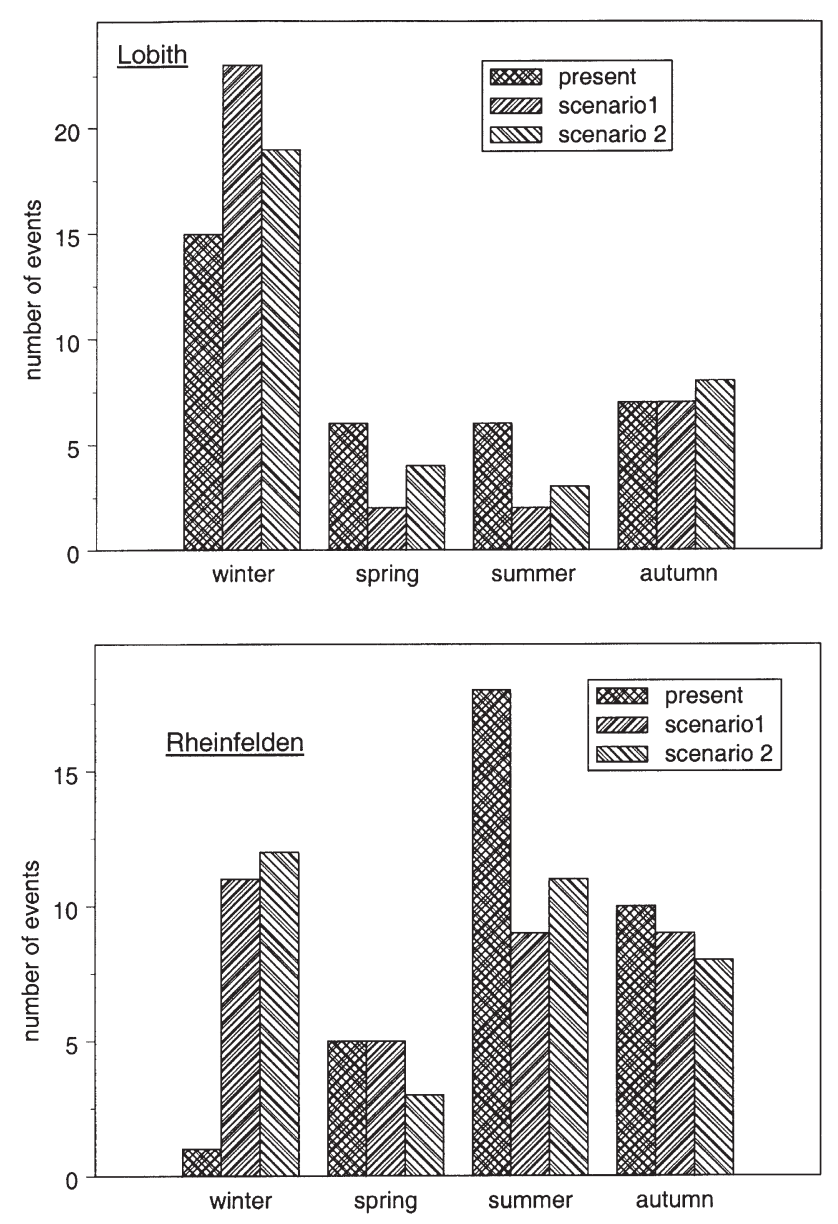

Fig. 15. Number of times that the annual maximum discharge occurs in the given season in the series of $35 \mathrm{yr}$, as simulated by RhineFlow for the present-day climate and in 2 scenario runs

applied to the RhineFlow hydrological model. The first scenario accounts for changes in the means of temperature and precipitation, the second scenario accounts for changes in both the mean and the variance of temperature and precipitation. With regard to the changes in the mean annual discharge, the difference between the 2 scenarios is small.

The mean annual discharge increases by a few percent only, but the seasonal cycle of the Rhine dis-

Table 5. Proportion (\%) of $10 \mathrm{~d}$ periods that the Rhine discharge at Lobith is below a certain threshold $\left(\mathrm{m}^{3} \mathrm{~s}^{-1}\right)$, as simulated by RhineFlow for the present-day climate and under Scenarios 1 and 2

\begin{tabular}{|lccc|}
\hline Threshold & Present & Scenario 1 & Scenario 2 \\
\hline 2300 & 56 & 58 & 61 \\
1600 & 29 & 38 & 40 \\
1000 & 8 & 16 & 18 \\
\hline
\end{tabular}


charge changes remarkably. In both scenarios the mean discharge decreases by about $30 \%$ in summer and increases by about $30 \%$ in winter. Changes are even larger on a monthly scale: in August, in particular, the discharge almost halves throughout the Rhine. The increase in the winter discharge is caused by the increased precipitation in combination with the reduced snow storage and increased early melt. The decrease in the summer discharge is related mainly to the decreased precipitation and, in the alpine area, to the increased evapotranspiration. The mean autumn and spring discharges of the Rhine do not change much.

The variability of discharge changes in both scenarios, but there is a marked difference between them. In Scenario 1, the CV of discharge increases significantly only in autumn, while in winter CV even decreases. In Scenario 2, on the other hand, the CV of discharge increases throughout the year, and this increase is statistically significant in 3 seasons out of 4 . The larger change in CV in Scenario 2 is accompanied by a larger change in the annual maximum discharge. The magnitude of the 20 yr maximum discharge event at Lobith, for instance, increases by $14 \%$ in Scenario 1 and by $29 \%$ in Scenario 2. The frequency of occurrence of low flows increases; the magnitude of changes is not sensitive to the chosen scenario.

These results are in qualitative agreement with the recent study of climate change impact on the Rhine discharge by Middelkoop (2000). An important distinction with that study is that the climate change scenarios used here are extracted from a recent regional climate model experiment, providing for a much finer spatial resolution. Changes in the variability of climatic inputs were not considered by Middelkoop (2000). Secondly, the meteorological input for the hydrological model is substantially updated, which potentially allows for a better treatment of spatial variability. These improvements increase our confidence in the resulting scenario discharge. According to the present study, the magnitude of changes in the discharge of the Rhine, in particular, the summer reduction of the flow, is much larger than previously projected. In the present-day climate, water shortage is not a major problem for the Rhine. In the future, however, the decrease in the mean discharge, particularly in August, and the increasing frequency of very low flows in summer may affect navigation, as well as water quality and supply. In winter, the scenarios suggest an increasing risk of floods, in particular if the increase in the CV of precipitation is taken into account.

The climate change scenarios used in this paper were based on a recent regional climate model experiment. Changes in temperature across Europe, as simulated by HadRM2, are consistent among most model- ling studies (IPCC 2001). The increase in precipitation during the non-summer seasons and its decrease in summer, as simulated by HadRM2, is a consistent result for mid-latitude Europe among coupled climate models (IPCC 2001; see also Arnell 1999, Arpe \& Roeckner 1999). The bias of the HadRM2 control climate simulation (Section 3.1) leaves, however, room for improvement. A reduction of bias is necessary to use the climatic series from the perturbed climate run directly as a scenario for the future climate. This will potentially provide an opportunity to account for changes in the temporal structure of the input series other than changes in the mean and variance.

The hydrological model used here is rather simple. As yet, it reproduces the mean seasonal flows well, and it does simulate changes in variability of discharge in both scenarios (Sections 4.2 and 4.3). On the other hand, there is a large bias in the present-day simulation of low flows. The highest discharges are also underestimated. This points to an incomplete description of relevant hydrological processes, which might question the applicability of RhineFlow outside the range of present-day conditions. There is therefore a need to improve the simulation of the extreme flows in the hydrological model. This work is currently in progress. The parametrization of changes in evapotranspiration via a temperature anomaly method is another pitfall of RhineFlow. The use of more physically based methods is preferable, but it requires a large additional amount of data.

The present results describe a plausible scenario for the Rhine discharge in 2080-2099. There is, however, a chain of uncertainties in the above procedure of assessing future discharge. The main uncertainties are related to the climate change scenario. These include a number of uncertainties regarding future emissions of greenhouse gases, plus uncertainties added at the stages of translation of emissions into forcing and of forcing into climate changes. With only 1 climate model integration used, little insight was given into this matter in the present paper. On the other hand, invoking of just another climate model would not add much to assessing the above uncertainties. In a comprehensive manner the uncertainties of climate change scenario can be accounted for within a probabilistic framework. Such a framework is only now emerging (Jones 2000, Palmer \& Räisänen 2002).

Acknowledgements. We wish to thank H. Buiteveld for his contribution to this research, G. P. Können and an anonymous reviewer for their detailed comments, F. J. M. van der Wel for his help with Fig. 1, and J. C. J. Kwadijk, who is the main developer of the RhineFlow model. The precipitation, temperature and evaporation data in this study were 
made available by the following institutions: Deutscher Wetterdienst, Service de la météorologie et de l'hydrologie de Luxembourg, Météo France and Swiss Meteorological Institute, via the CHR meteorological database. J. N. M. Stricker kindly provided the Hupselse Beek data. The HadCM2/HadRM2 data were supplied by the Climate Impacts LINK project, Department of the Environment, Contract EPG 1/11/16, on behalf of the Hadley Centre and UK Meteorological Office. This research was, in part, supported by the EU Environment and Climate Research Programme (contract: EVK1-CT-2000-00075 SWURVE) and the Institute for Inland Water Management and Waste Water Treatment (RIZA).

Appendix 1. Scenario 2 for precipitation from the Weibull distribution

The Weibull distribution is a flexible 2-parameter distribution providing a reasonable fit to the $10 \mathrm{~d}$ rainfall amounts. The distribution is given by:

$$
F(x)=\operatorname{Pr}(X \leq x)=1-\exp \left[-(x / \alpha)^{c}\right], \quad x \geq 0
$$

Here $\alpha$ is the scale parameter and $c$ the shape parameter. The distribution function can be easily inverted. For the $p$ th quantile $x_{p}$ we find:

$$
x_{p}=\alpha[-\ln (1-p)]^{1 / c}
$$

In the observed data, the Weibull parameters $\alpha_{0}$ and $c_{0}$ were chosen such that the distribution preserves the mean and variance, and hence CV. This was done for each $10 \mathrm{~d}$ period of the year and for each HadRM2 grid box. For Scenario 2, the mean and CV were adjusted according to their relative changes in the HadRM2 experiment and then the Weibull parameters $\alpha_{s}$ and $C_{s}$ were calculated. It was further assumed that if the observed $10 \mathrm{~d}$ amount $x_{0}$ corresponds to the $p$ th quantile in the observational series, then the scenario value $x_{\mathrm{s}}$ corresponds to the $p$ th quantile in the scenario series. From Eqs. (A1) \& (A2) it follows:

$x_{S}=\alpha_{s}[-\ln (1-p)]^{1 / c_{s}}=\alpha_{s}\left(-\ln \left\{\exp \left[-\left(x_{0} / \alpha_{0}\right)^{c_{0}}\right]\right\}\right)^{1 / c_{s}}=\alpha_{s}\left(x_{0} / \alpha_{0}\right)^{c_{0} / c_{s}}$

If $C_{S}=C_{0}$, then Scenario 1 (proportional adjustment) is obtained. An increase in $\mathrm{CV}$ as found in Section 3.2.3 implies that $C_{S}<C_{0}$, and thus the exponent in Eq. (A3) is greater than 1 . This leads to a relatively large adjustment of high $10 \mathrm{~d}$ precipitation amounts compared to proportional adjustment. It also leads to an increase in the proportion of very small $10 \mathrm{~d}$ precipitation amounts, being somewhat in line with the increase in the number of dry days in the HadRM2 climate change experiment.

The non-linearity of Eq. (A3) hampers its direct application to the RhineFlow grid. The changes in precipitation resulting from aggregating the perturbed values from the RhineFlow grid within a HadRM2 box may differ from those originally projected by HadRM2. To avoid this inconsistency, the ratios $x_{S} / x_{0}$ from Eq. (A3) were computed for the observed precipitation amounts aggregated within each HadRM2 grid box, and then the scenario series were produced by multiplying the observed precipitation amounts in each grid box of RhineFlow with the ratio $x_{S} / x_{0}$ from the corresponding HadRM2 grid box.

\section{LITERATURE CITED}

Arnell NW (1999) The effect of climate change on hydrological regimes in Europe: a continental perspective. Global Environ Change 9:5-23

Arpe K, Roeckner E (1999) Simulation of the hydrological cycle over Europe: model validation and impacts of increasing greenhouse gases. Adv Water Resour 23:105-119

Beersma JJ, Buishand TA (1999) A simple test for equality of variances in monthly climate data. J Clim 12:1770-1779

Bergström S, Carlsson B, Gardelin M, Lindström G, Pettersson A, Rummukainen M (2001) Climate change impacts on runoff in Sweden - assessments by global climate models, dynamical downscaling and hydrological modelling. Clim Res 16:101-112

Brandsma T (1995) Hydrological impact of climate change, a sensitivity study for the Netherlands. PhD thesis, Delft University of Technology

Brown RD (2000) Northern hemisphere snow cover variability and change, 1915-1997. J Clim 13:2339-2355

de Bruin HAR, Stricker JNM (2000) Evaporation of grass under non-restricted soil moisture conditions. Hydrol Sci J 45:391-406

Durman CF, Gregory JM, Hassell DC, Jones RG, Murphy JM (2001) A comparison of extreme European daily precipitation simulated by a global and a regional climate model for present and future climates. Q J R Meteorol Soc 127: 1005-1015

Frei C, Schär C (2001) Detection probability of trends in rare events: theory and application to heavy precipitation in the Alpine region. J Clim 14:1568-1584

Frei C, Schär C, Luthy D, Davies H (1998) Heavy precipitation processes in a warmer climate. Geophys Res Lett 25: 1431-1434

Gallardo C, Arribas A, Prego JA, Gaertner MA, de Castro M (2001) Multi-year simulations using a regional-climate model over the Iberian Peninsula: current climate and doubled $\mathrm{CO}_{2}$ scenario. Q J R Meteorol Soc 127: 1659-1681

Gellens D (2000) Trend and correlation analysis of $k$-day extreme precipitation over Belgium. Theor Appl Climatol 66:117-129

Grabs W (ed) (1997) IMPACT of climate change on hydrological regimes and water resources management in the Rhine basin. CHR report I-16, CHR Secretariat, Lelystad

Groisman PYa, Knight RW, Karl TR (2001) Heavy precipitation and high streamflow in the contiguous United States: trends in the twentieth century. Bull Am Meteorol Soc 82: $219-246$

Harter HL (1984) Another look at plotting positions. Commun Stat Theor Methods 13:1613-1633

Harter HL, Moore AH (1968) Maximum-likelihood estimation, from doubly censored samples, of the parameters of the first asymptotic distribution of extreme values. J Am Stat Assoc 63:889-901

IPCC (1996) Climate change 1995: the science of climate change, contribution of Working Group I to the Second Assessment Report of the Intergovernmental Panel on Climate Change. Houghton JT, Meira Filho LG, Callander BA, Harris N, Kattenberg A, Maskell K (eds). Cambridge University Press, Cambridge

IPCC (2001) Climate change 2001: the scientific basis: contribution of Working Group I to the Third Assessment Report of the Intergovernmental Panel on Climate Change. Houghton JT, Ding Y, Griggs DJ, Noguer M, van der Linden PJ, Dai X, Maskell K, Johnson CA (eds). Cambridge University Press, Cambridge 
Johns TC, Canell RE, Crossley JF, Mitchell JFB, Senior CA, Tett SFB, Wood RA (1997) The second Hadley Centre coupled ocean-atmosphere GCM: model description, spinup and validation. Clim Dyn 13:103-134

Jones PD, Reid PA (2001) Assessing future changes in extreme precipitation over Britain using regional climate model integrations. Int J Climatol 21:1337-1356

Jones RN (2000) Analysing the risk of climate change using an irrigation demand model. Clim Res 14:89-100

Kwadijk J (1993) The impact of climate change on the discharge of the river Rhine. KNAG/Netherlands Geographical Studies Publ. 171, Utrecht

Kwadijk J, Rotmans J (1995) The impact of climate change on the river Rhine: a scenario study. Clim Change 30:397-426

McKenney MS, Rosenberg NJ (1993) Sensitivity of some potential evapotranspiration estimation methods to climate change. Agric For Meteorol 64:81-110

Mearns LO, Giorgi F, McDaniel L, Shields C (1995) Analysis of the diurnal range and variability of daily temperature in a nested modeling experiment: comparison with observations and $2 \times \mathrm{CO}_{2}$ results. Clim Dyn 11:193-209

Meehl GA, Zwiers F, Evans J, Knutson T, Mearns LO, Whetton $\mathrm{P}$ (2000) Trends in extreme weather and climate events: issues related to modeling extremes in projections of future climate change. Bull Am Meteorol Soc 81:427-436

Middelkoop H (ed) (2000) The impact of climate change on the river Rhine and the implications for water management in the Netherlands. Summary report of the NRP project 952210. RIZA Report 2000.010, RIZA, Lelystad

Milly PCD, Wetherald RT, Dunne KA, Delworth TL (2002) Increasing risk of great floods in a changing climate. Nature 415:514-517

Nash JE, Sutcliffe JV (1970) River flow forecasting through conceptual models 1: a discussion of principles. J Hydrol 10:282-290

Noguer M, Jones R, Murphy J (1998) Sources of systematic errors in the climatology of a regional climate model over Europe. Clim Dyn 14:691-712

Editorial responsibility: Hans von Storch, Geesthacht, Germany
Oerlemans J (1994) Quantifying global warming from the retreat of glaciers. Science 264:243-245

Osborn TJ, Hulme M, Jones PD, Basnett TA (2000) Observed trends in the daily intensity of United Kingdom precipitation. Int J Climatol 20:347-364

Palmer TN, Räisänen J (2002) Quantifying the risk of extreme seasonal precipitation events in a changing climate. Nature 415:512-514

Räisänen J, Joelsson R (2001) Changes in average and extreme precipitation in two regional climate model experiments. Tellus 53A:547-566

Robinson DA (1997) Hemispheric snow cover and surface albedo for model validation. Ann Glaciol 25:241-245

Schneeberger C, Albrecht O, Blatter H, Wild M, Hock R (2001) Modelling the response of glaciers to a doubling in atmospheric $\mathrm{CO}_{2}$ : a case study of Storglaciaren, north Sweden. Clim Dyn 17:825-834

Schönwiese CD, Rapp J (1997) Climate trend atlas of Europe based on observations 1891-1990. Kluwer Academic Publisher, Dordrecht

Stricker JNM (1981) Methods of estimating evapotranspiration from meteorological data and their applicability in hydrology. In: Hooghart C (ed) Evaporation in relation to hydrology. Proceedings and Information no. 28. Commission for Hydrological Research TNO, The Hague, p 25-37

Thornthwaite CW, Mather JR (1957) Instructions and tables for computing potential evapotranspiration and the water balance. In: Publications in climatology, Vol 10. Laboratory of Climatology, Drexel Institute of Technology, Centerton, NJ, p 183-243

van Deursen WPA, Kwadijk J (1993) RHINEFLOW: an integrated GIS water balance model for the river Rhine. In: Kovar K, Nachtnebel HP (eds) Application of Geographic Information Systems in hydrology and water resources management. IAHS Publ. 211, IAHS Press, Institute of Hydrology (now: Centre for Ecology and Hydrology), Wallingford, p 507-519

Submitted: July 7, 2002; Accepted: November 18, 2002 Proofs received from author(s): March 27, 2003 